\title{
Diazo coupling for the determination of selexipag by visible spectrophotometry
}

\author{
Giri Prasad Gorumutchu', Venkata Nadh Ratnakaram² \\ ${ }^{1}$ Department of Chemistry, Acharya Nagarjuna University, Guntur, Andhra Pradesh, India, ${ }^{2}$ Department of \\ Chemistry, GITAM University, Bengaluru, Karnataka, India
}

\begin{abstract}
Aim and Objective: The aim and objective of this study were to develop a spectrophotometric method for the assay of selexipag (selective IP prostacyclin receptor agonist indicated for the treatment of pulmonary arterial hypertension) in pure and pharmaceutical formulations so that it will be an alternative quantitative method to chromatographic methods which require large quantities of organic solvents, where some are with hazardous and toxic properties. Materials and Methods: The method is based on the diazo coupling of selexipag with diazotized p-nitroaniline in alkaline medium to form a stable green-colored and water-soluble azo dye with a maximum absorption at $510 \mathrm{~nm}$. Optimization of reaction conditions was carried out to get highly sensitive and stable colored complex. Results and Discussion: Beer's law is obeyed over the concentration range of $2-12 \mu \mathrm{g} / \mathrm{mL}$ with a molar absorptivity of $3.33 \times 10^{4} \mathrm{~L} / \mathrm{mol} / \mathrm{cm}$. The limit of detection was $0.35 \mu \mathrm{g} / \mathrm{mL}$ and limit of quantification was $1.0 \mu \mathrm{g} / \mathrm{mL}$. The results demonstrated that the procedure is accurate, precise, and reproducible (relative standard deviation $<2 \%$ ). Conclusions: This method was tested and validated for various parameters according to the current ICH guidelines.
\end{abstract}

Key words: Diazo coupling, p-nitroaniline, selexipag, validation, visible spectrophotometry

\section{INTRODUCTION}

$\mathrm{S}$ elexipag is a selective IP prostacyclin receptor agonist and suggested for the treatment of pulmonary arterial hypertension to delay disease progression and reduce the risk of hospitalization. ${ }^{[1]}$ Selexipag is rapidly absorbed after oral administration and hydrolyzed to the pharmacologically more active metabolite ACT-333679. ${ }^{[2]}$ It was synthesized by Nippon Shinyaku and later jointly developed with Actelion Pharmaceuticals Ltd. 2-\{4-[(5,6-diphenylpyrazin-2-yl)(propan-2-yl) amino]butoxy $\}-\mathrm{N}$-methanesulfonylacetamide is the chemical name of selexipag [Figure 1]. ${ }^{[3]}$

Thorough literature survey makes it clear that no visible spectrophotometric method is reported so far for the determination of selexipag, but only one high-performance liquid chromatographic (HPLC) method was published. ${ }^{[4]}$ Therefore, the current study reports the development and validation of a flexible visible spectrophotometric method for the determination of selexipag in bulk drug and tablet dosage formulations using a diazotized coupling reaction.

\section{MATERIALS AND METHODS}

Analytical reagent grade chemicals were used throughout the investigation. Double distilled water was used, and solutions were freshly prepared. Absorbance was measured using double beam UV-Visible Spectrophotometer (TECHCOMP, UV 2310) equipped with HITACHI software version 2.0. Quartz cuvettes (10 mm path length). Samples were weighed using Shimadzu AUX-220 balance. Spectroscopic measurements were conducted at room temperature $\left(25 \pm 5^{\circ} \mathrm{C}\right)$.

\section{Preparation of Reagents}

Para nitroaniline (PNA) solution $\left(7.24 \times 10^{-3} \mathrm{M}\right)$ : Accurately $100 \mathrm{mg}$ of PNA was weighed and was taken in a $100 \mathrm{~mL}$

\author{
Address for correspondence: \\ Dr. Venkata Nadh Ratnakaram, Department of Chemistry, \\ GITAM University, Bengaluru Campus, Nagadenahalli, \\ Doddaballapur Taluk, Bengaluru - 561 203, Karnataka, \\ India. Phone: +91-9902632733. \\ E-mail: doctornadh@yahoo.co.in
}

Received: 06-07-2018

Revised: 07-12-2018

Accepted: 16-12-2018 
volumetric flask. It was dissolved in $20 \mathrm{~mL}$ of one normal $\mathrm{HCl}$ solution and made up to the mark with distilled water.

Sodium nitrite solution $\left(1.45 \times 10^{-2} \mathrm{M}\right)$ : Accurately $100 \mathrm{mg}$ of $\mathrm{NaNO}_{2}$ was weighed and was taken in a $100 \mathrm{~mL}$ volumetric flask. It was dissolved in distilled water and made up to the mark.

Sodium hydroxide solution $(1 \mathrm{M})$ : Accurately $4 \mathrm{~g}$ of $\mathrm{NaOH}$ was weighed and was taken in a $100 \mathrm{~mL}$ volumetric flask. It is dissolved in distilled water and made up to the mark.

\section{RESULTS AND DISCUSSION}

\section{Chromophore and its Absorption Spectrum}

The developed chromophore for the determination of selexipag by visible spectrophotometry has shown a characteristic absorption maximum at $510 \mathrm{~nm}$ [Figure 2].

\section{Optimization of Reaction Conditions}

Reaction conditions affecting the development, sensitivity, and stability of colored product are volume/concentration of

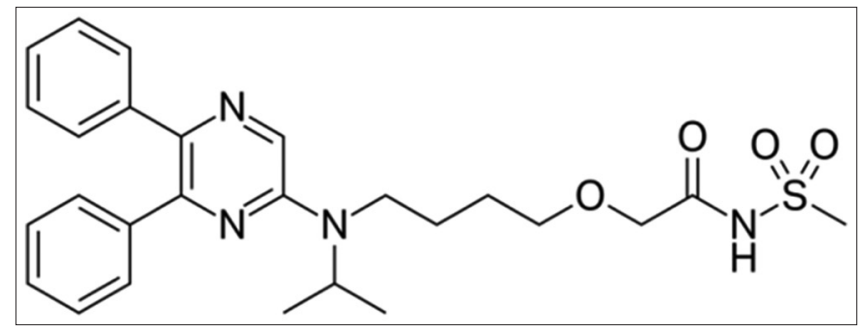

Figure 1: Chemical structure of selexipag solutions (PNA, acid, sodium nitrite, and sodium hydroxide), time for the formation and stability of colored product, and temperature. Variation of reaction conditions was carried out to optimize them. Color species absorbance was measured in the establishment of optimum conditions by changing the condition of one parameter at a time and by maintaining fixed conditions for others.

\section{Effect of Type and Volume of Base}

The primary experiments show that reasonable colored intensity was observed with p-nitroaniline in the alkaline medium. Although most of the researchers reported the production of higher intensity in the presence of sodium hydroxide,,$^{[5-7]}$ few others also reported the best results with sodium carbonate, for example, in the estimation of Vitamin $B 6^{[8]}$ and paracetamol. ${ }^{\left[{ }^{[9]}\right.}$ Hence, an effort was made to learn the effect of type of alkali on the intensity of formed azo dye by recording absorbance using one molar concentration solution of each alkali [Table 1]. Maximum absorption values were found with sodium hydroxide, and hence, it was used in consequent studies. Volume of one molar sodium hydroxide addition is fixed as $1 \mathrm{~mL}$ as lower absorption was observed on both the sides of that volume [Figure 3].

\begin{tabular}{lc}
\multicolumn{2}{c}{ Table 1: Effect of type of base } \\
\hline Alkali used (1 M) & Absorbance* \\
\hline $\mathrm{NaOH}$ & 0.547 \\
$\mathrm{KOH}$ & 0.521 \\
$\mathrm{Na}_{2} \mathrm{CO}_{3}$ & 0.306 \\
$\mathrm{NaHCO}_{3}$ & Slow development of turbidity \\
\hline
\end{tabular}

${ }^{*}$ At $8 \mu \mathrm{g} / \mathrm{mL}$ selexipag

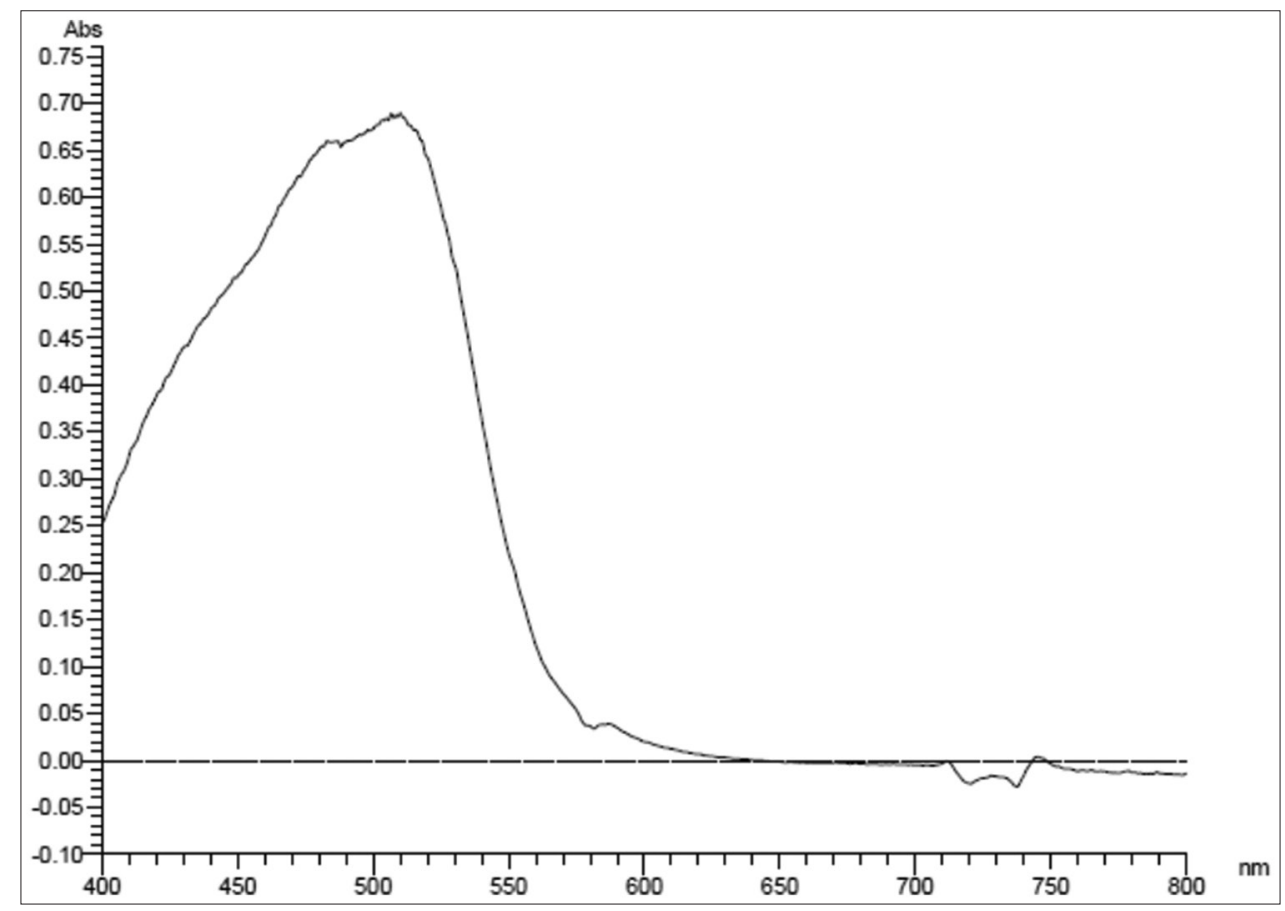

Figure 2: Visible spectrum of green-colored and water-soluble azo dye of selexipag 


\section{Effect of Concentrations of PNA and $\mathrm{NaNO}_{2}$}

Absorbance was increased up to $0.2 \mathrm{M}$ acid concentration in PNA solution and then decreased. Probably, more number of amine molecules occur in their ionic form at higher concentration of acid, and hence, the rate of coupling is hampered. Higher intensity of color was found when volumes of PNA $\left(7.24 \times 10^{-3} \mathrm{M}\right)$ and $\mathrm{NaNO}_{2}\left(1.45 \times 10^{-2} \mathrm{M}\right)$ solutions were in the range of $0.8-1.0 \mathrm{~mL}$. Persistent absorbance was observed even at higher volumes of sodium nitrite, whereas fluctuating results were observed with PNA [Figure 3].

\section{Effect of Time on Development of Color and Its Stability}

Different time intervals (2-90 $\mathrm{min}$ ) were chosen to study the optimum time required for the formation (i.e., for coupling reaction) and its stability of color at room temperature. Absorbance values [Table 2] show that maximum intensity of color is achieved within $5 \mathrm{~min}$ and is stable almost up to $1 \mathrm{~h}$.

\section{Sequence of Addition of Reagents}

The effect of the sequence of addition of reagents on the formation of chromogen was studied. The observed absorbance values [Table 3] indicate that the sequence "diazotized pNA (DPNA) + Drug + Base" can be considered for the addition of reactants and reagents. ${ }^{[10]}$

Effect of temperature on colored complex stability was inspected at various temperatures and found that the

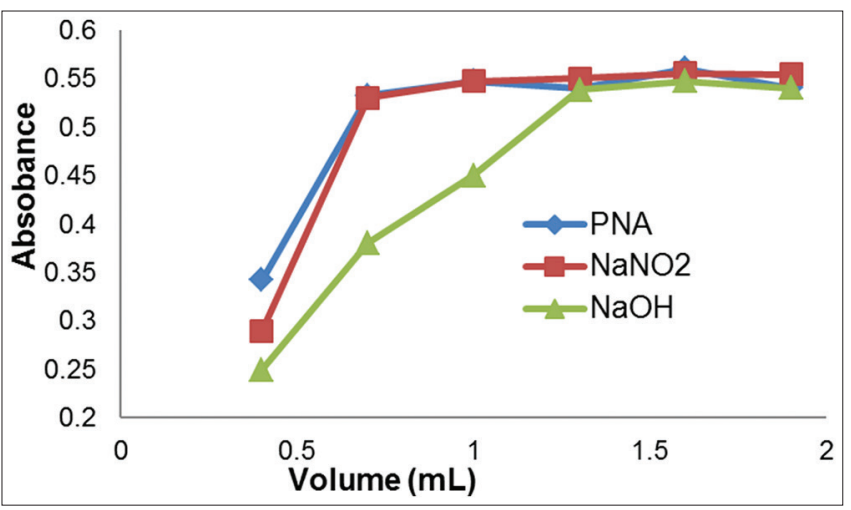

Figure 3: Optimization of volumes of para nitroaniline, $\mathrm{NaNO}_{2}$, and $\mathrm{NaOH}$ solutions

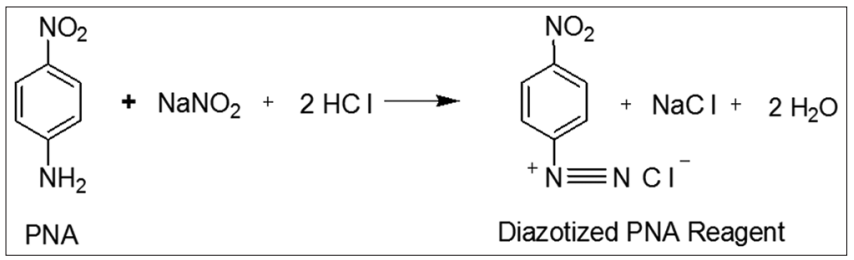

Figure 4: Formation of diazotized p-nitroaniline absorbance values are reproducible in the range $20-35^{\circ} \mathrm{C}$. However, colored solution was found to be unstable beyond that temperature range. Hence, all the studies were carried out at room temperature.

Table 2: Effect of Time on coupling reaction

\begin{tabular}{lc} 
Time $(\mathrm{min})$ & Absorbance* $^{*}$ \\
\hline 2 & 0.518 \\
5 & 0.547 \\
10 & 0.541 \\
15 & 0.538 \\
30 & 0.538 \\
60 & 0.535 \\
\hline
\end{tabular}

${ }^{*}$ At $8 \mu \mathrm{g} / \mathrm{mL}$ selexipag

Table 3: Effect of reactants addition sequence on absorbance

\begin{tabular}{lc}
$\begin{array}{l}\text { Reactants and reagents } \\
\text { addition sequence }\end{array}$ & Absorbance* $^{*}$ \\
\hline Drug+Base+DPNA & 0.410 \\
DPNA+Base+Drug & 0.493 \\
DPNA+Drug+Base & 0.547 \\
\hline
\end{tabular}

${ }^{*}$ At $8 \mu \mathrm{g} / \mathrm{mL}$ selexipag. DPNA: Diazotized para nitroaniline

Table 4: Calibration values of selexipag

\begin{tabular}{lc} 
Concentration $(\mu \mathrm{g} / \mathrm{mL})$ & Absorbance* $^{*}$ \\
\hline 2 & 0.131 \\
4 & 0.259 \\
6 & 0.408 \\
8 & 0.547 \\
10 & 0.682 \\
12 & 0.816 \\
\hline
\end{tabular}

${ }^{*}$ Average of three determinations

Table 5: Optical and regression parameters

Parameter Value

Optical characteristics

Apparent molar absorptivity

3. $33 \times 10^{4} \mathrm{~L} / \mathrm{mol} / \mathrm{cm}$

Sandell's sensitivity

$0.015 \mu \mathrm{g} / \mathrm{cm}^{-2}$

Regression analysis

Slope

0.069

Intercept

$-0.009$

Regression coefficient $(r)$

0.999

Validation parameters

$\lambda_{\text {max }}$

$510 \mathrm{~nm}$

Beer's law limit

Limit of detection

2-12 Linearity, $\mu \mathrm{g} / \mathrm{mL}$

$0.35 \mu \mathrm{g} / \mathrm{mL}$

Limit of quantitation $\mu \mathrm{g} / \mathrm{mL}$

$1.0 \mu \mathrm{g} / \mathrm{mL}$ 


\section{Optimized Method Procedure}

Into a series of $25 \mathrm{~mL}$ volumetric flasks, $1.0 \mathrm{~mL}$ each of PNA and $\mathrm{NaNO}_{2}$ solutions was successively added and allowed to stand for $5 \mathrm{~min}$. Aliquot of standard working solution of drug $(100 \mu \mathrm{g} / \mathrm{mL})$ was transferred into volumetric flasks. Then, $1.6 \mathrm{~mL}$ of $\mathrm{NaOH}$ solution was added and the volume in each flask was made up to the mark with distilled water. The absorbance of the generated green-colored chromophore was measured at $\lambda_{\max } 510 \mathrm{~nm}$ against the reagent blank after 5 min of mixing.

\section{Chromophore Formation and Chemistry}

Oxidation reactions play a pivotal role in the determination of pharmaceutical drugs..$^{[11,12]}$ Of those, azo dye formation is the well-exploited chemical reaction for the determination of drugs by derivatization. $\lambda_{\max }$ of azo dyes is outspread into the visible region due to the linkage of two aromatic rings by diazo group which results in conjugation extension. Coupling of a diazonium salt to activated/ neutral/deactivated skeleton produces an azo dye, where a diazonium ion can be considered as an electrophile. Diazonium ion activity dictates the azo dye formation rate. Coupling reaction of diazonium ion with deactivated or neutral skeleton is promoted due to the presence of a substituent with a nature of resilient electron withdrawing on diazonium ion. ${ }^{[13,14]} \mathrm{pNA}$ is one of the prominent organic chromophores. It is a member of a specific class of compounds known as "push or pull," in which an electrondonor ( $\mathrm{NH}_{2}$ group) and electron acceptor $\left(\mathrm{NO}_{2}\right.$ group) are joined through $\pi$-conjugated system (phenyl ring). ${ }^{[15]}$ pNA is one of the diazotizable aromatic amines and forms DPNA by the reaction of nitrous acid (formed from sodium nitrite and $\mathrm{HCl}$ ) with it [Figure 4]. ${ }^{[16,17]}$

In the subsequent step, DPNA is accountable to the formation of colored azo dyes due to its coupling reaction with selexipag. This diazo coupling can be regarded as a condensation reaction coupled with the elimination of a proton due to the reaction between DPNA and a compound possessing an

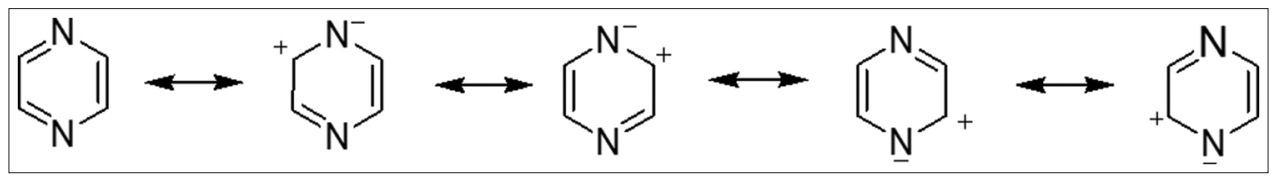

Figure 5: Resonance hybrid of pyrazine

\begin{tabular}{|c|c|c|c|c|}
\hline \multicolumn{5}{|c|}{ Table 6: Recovery values } \\
\hline $\begin{array}{l}\text { Level of } \\
\text { recovery (\%) }\end{array}$ & $\begin{array}{l}\text { Total amount of drug } \\
(\mu \mathrm{g} / \mathrm{mL})(\mathrm{a}+\mathrm{b}) \\
(\text { Theoretical) }\end{array}$ & $\begin{array}{c}\text { Amount of drug recovered } \\
(\mu \mathrm{g} / \mathrm{mL})(\text { Practical })\end{array}$ & $\begin{array}{l}\text { Statistical } \\
\text { evaluation }\end{array}$ & $\begin{array}{c}\% \text { Recovery=Practical } \times 100 / \\
\text { Theoretical }\end{array}$ \\
\hline \multirow[t]{3}{*}{50} & 6 & 5.91 & Mean: 5.93 & 98.50 \\
\hline & 6 & 5.95 & SD: 0.02 & 99.17 \\
\hline & 6 & 5.92 & \% RSD: 0.29 & 98.67 \\
\hline \multirow[t]{3}{*}{100} & 8 & 7.94 & Mean: 7.91 & 99.25 \\
\hline & 8 & 7.89 & SD: 0.02 & 98.62 \\
\hline & 8 & 7.91 & \% RSD: 0.26 & 98.87 \\
\hline \multirow[t]{3}{*}{150} & 12 & 11.98 & Mean: 12.03 & 99.83 \\
\hline & 12 & 12.09 & SD: 0.05 & 100.75 \\
\hline & 12 & 12.01 & \% RSD: 0.39 & 100.08 \\
\hline
\end{tabular}

Nominal concentration used $(\mu \mathrm{g} / \mathrm{mL})(\mathrm{a}): 4$ for all recovery levels. Amount of drug added $(\mu \mathrm{g} / \mathrm{mL})(\mathrm{b}): 2,4$, and 8 for $50 \%, 100 \%$, and $150 \%$, respectively

Table 7: Precision readings

\begin{tabular}{lcccc}
$\begin{array}{l}\text { Concentration of } \\
\text { selexipag }(\boldsymbol{\mu g} / \mathbf{m L})\end{array}$ & \multicolumn{4}{c}{ Concentration* } \\
\cline { 2 - 5 } & $\begin{array}{c}\text { Intraday } \\
\text { Mean } \pm \text { SD }(\mu \mathrm{g} / \mathbf{m L})\end{array}$ & $\%$ RSD & $\begin{array}{c}\text { Interday } \\
\text { Mean } \pm S D(\mu \mathrm{g} / \mathrm{mL})\end{array}$ & $\%$ RSD \\
\hline 2 & $2.05 \pm 0.02$ & 0.97 & $2.08 \pm 0.02$ & 0.96 \\
8 & $8.04 \pm 0.09$ & 1.12 & $8.11 \pm 0.09$ & 1.11 \\
12 & $11.95 \pm 0.11$ & 0.92 & $11.95 \pm 0.11$ & 0.92 \\
\hline
\end{tabular}

${ }^{*}$ Average of six determinations. RSD: Relative standard deviation 
active hydrogen atom. The two possible substitution points on selexipag are benzene ring and pyrazine ring.

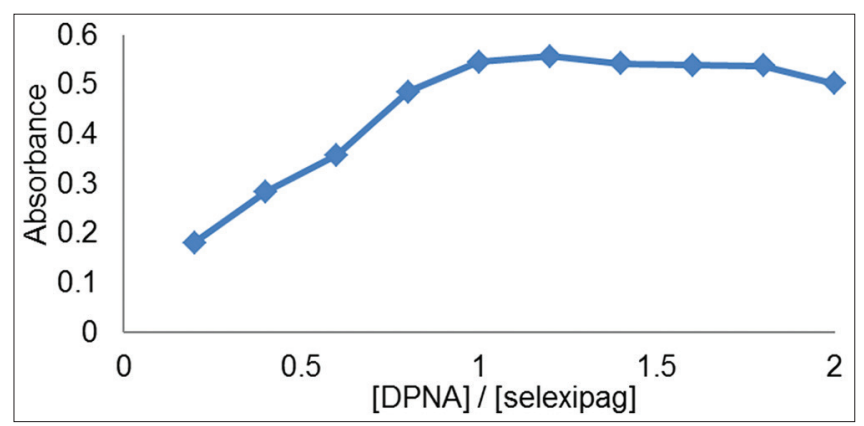

Figure 6: Mole ratio method for complex formation at $8 \mu \mathrm{g} / \mathrm{mL}$ of selexipag
Pyrazine is aromatic in character and has lower resonance energy compared to benzene. It undergoes electrophilic aromatic substitution on one of its resonance hybrids, which are shown in Figure 5. From its canonical forms, four points of electron deficient are visible at 2, 3, 5, and 6 positions $^{[18]}$ indicating the possible attack by nucleophilic reagents at those positions. As DPNA is considered as an electrophile, the possibility of its attachment to pyrazine structure can be eliminated. Hence, benzene ring is the only left over option for attachment. To know more about the nature of the formed dye (i.e., the number of DPNA substitutions on the drug), reaction ratio between selexipag and DPNA was determined ${ }^{[19]}$ Figure 6 shows that the ratio is 1:1, and hence, the scheme [Figure 7] illustrates the proposed mechanism. The substitution of DPNA is directed preferably to the para<smiles>CC(C)N(CCCCOCC(=O)NS(C)(=O)=O)c1cnc(-c2ccccc2)c(-c2ccccc2)n1</smiles>

Figure 7: Formation of green-colored and water-soluble azo dye 
position to the attached active group, and if para position is already occupied, then it will be directed to the ortho. Hence, DPNA is directed to the para position on the benzene ring which is further attached to pyrazine.

\section{Validation of Proposed Method}

The proposed was validated as per the existing $\mathrm{ICH}$ guidelines. $^{[20]}$

\section{Linearity and range}

A graph was plotted between absorbance and concentrations (2-12 $\mu \mathrm{g} / \mathrm{mL})$ to obtain a linear calibration curve [Figure 8]. Three independent measurements were carried out for each concentration, and their mean value was indicated as a point of the calibration graph [Table 4]. The correlation coefficient of linear regression equation $(y=0.069 x-0.0095)$ was $>0.999$, and hence, linearity of the proposed analytical method was tested. Different optical and regression parameters are shown in Table 5.

\section{Accuracy}

Accuracy of the proposed method was tested by determining percent recovery values. This was performed by adding

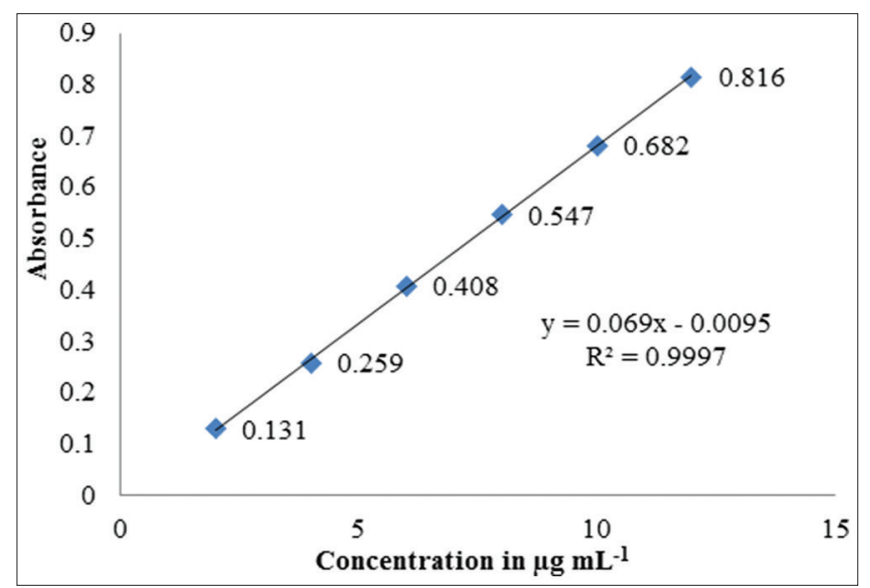

Figure 8: Calibration graph of selexipag

Table 8: Ruggedness data of selexipag

\begin{tabular}{lcc} 
Concentration of & \multicolumn{2}{c}{ Concentration* } \\
\cline { 2 - 3 } selexipag $(\mu \mathrm{g} / \mathrm{mL})$ & Mean \pm SD $(\mu \mathrm{g} / \mathrm{mL})$ & $\%$ RSD \\
\hline 2 & 2.04 & 0.98 \\
8 & 8.06 & 1.12 \\
12 & 11.92 & 0.67 \\
\hline
\end{tabular}

${ }^{*}$ Average of six determinations. RSD: Relative standard deviation different amounts $(50 \%, 100 \%$, and $150 \%)$ of bulk samples of selexipag to $4 \mu \mathrm{g} / \mathrm{mL}$ to maintain the total amount of drug (theoretical) concentration within the linearity range. The percentage recovery values were in the range of 98.50-100.75 [Table 6]. A high level of accuracy for the proposed method is evident as standard deviation (SD) values are lower and \% relative $\mathrm{SD}(\% \mathrm{RSD})$ values are $<1$.

\section{Precision}

Intra- and inter-day precision were studied by selecting three different concentrations of selexipag in the linear range $(2-12 \mu \mathrm{g} / \mathrm{mL})$. Of the six independent series, analysis was carried out on the same day and on 6 consecutive days for each concentration [Table 7]. Satisfactory precision of the method is evident from lower \% RSD values in the range of 0.92-1.12 and $0.92-1.11$, respectively, for intra- and inter-day studies.

\section{Ruggedness}

The developed method was evaluated for the ruggedness by carrying out assay at different concentrations $(2,8$, and $12 \mu \mathrm{g} /$ $\mathrm{mL}$ ) of selexipag by two different analysts on different days under the same optimized conditions. No significant difference between the analyst values indicates the reproducibility of results, and hence, the proposed method is rugged [Table 8].

\section{Detection of limit of detection (LOD) and limit of quantification (LOQ)}

The sensitivity of the proposed method was confirmed from the calculations of LOD and LOQ. Signal-to-noise ratio method $^{[21]}$ was used to determine LOD and LOQ for selexipag from the values of $\mathrm{S}$ (slope of the calibration curve) and $\sigma$ (SD of the response) as per the ICH guidelines. ${ }^{[20]}$

$$
\begin{gathered}
\mathrm{LOD}=3.3 \times \sigma / \mathrm{S}=0.35 \mu \mathrm{g} / \mathrm{mL} \text { and } \\
\mathrm{LOQ}=10 \times \sigma / \mathrm{S}=1.01 \mu \mathrm{g} / \mathrm{mL} .
\end{gathered}
$$

\section{Analysis of Pharmaceutical Formulations}

Chromophore was derived from the extracts of selexipag tablets $\left(\mathrm{Uptravi}^{\circledR}\right)$, and absorbance values were measured to determine the amount of API present in tablet (on an average weight basis) [Table 9]. Without any interference from common excipients, the amount of selexipag in pharmaceutical formulations can be effectively determined by the proposed method because the recovery values of the API are good. As spectrophotometric methods are preferred in quality control laboratories of developing countries, ${ }^{[22-27]}$ the present method can be used for routine analysis.

\begin{tabular}{lcccc}
\multicolumn{4}{c}{ Table 9: Estimation of selexipag from its formulation } \\
Formulation & Labeled amount $(\boldsymbol{\mu g})$ & Amount found* Mean \pm SD $(\boldsymbol{\mu g})$ & $\%$ Drug recovered & \% RSD \\
\hline${\text { Uptravi }{ }^{\circledR} \text { Tablets }}^{*}$ Average of three determinations. RSD: Relative standard deviation & $198.58 \pm 0.76$ & 99.92 & 0.38 \\
\hline${ }^{*}$ Avera
\end{tabular}




\section{CONCLUSIONS}

The proposed method exploits the application of diazo coupling reaction for the determination of selexipag. It is simple, accurate, fast, and inexpensive. It does not require the usage of relatively large amounts of potentially hazardous and expensive organic solvents. Data of recovery study indicate the reproducibility and accuracy of the current method. The proposed methods can be used for routine quality control of selexipag in bulk drug and tablet formulation in the pharmaceutical laboratories and industries as an alternative to the HPLC and liquid chromatography-tandem mass spectrometry methods.

\section{REFERENCES}

1. Chakinala MM, Hemnes AR, Highland $\mathrm{K}$, Kim NH, Farber HW, Chin K, et al. Uptravi ${ }^{\circledR}($ SelexiPag): The users drug registry (SPHERE): A US-based, prospective drug registry of selexipag in clinical practice. In A68. WOW: Pharmacological treatment of pulmonary hypertension. Am Thorac Soc 2017;195:A2295.

2. Mubarak KK. A review of prostaglandin analogs in the management of patients with pulmonary arterial hypertension. Respir Med 2010;104:9-21.

3. Simonneau G, Torbicki A, Hoeper MM, Delcroix M, Karlócai K, Galiè N, et al. Selexipag: An oral, selective prostacyclin receptor agonist for the treatment of pulmonary arterial hypertension. Eur Respir J 2012;40:874-80.

4. Damireddy S, Pravalika K, Praveen M, Sathish G, Anusha M. Method development and validation of selexipag in its bulk and dosage form by rp-HPLC. Int J Pharm Biol Sci 2017;7:84.

5. Mallikarjuna H, Lokesh KS, Shivaprasad KH, Venugopala KR. Novel spectrophotometric methods for the assay of an antiepileptic oxcarbazepine. World J Pharm Pharm Sci 2014;3:815-31.

6. Othman NS, Huseen AM. Spectrophotometric determination of L-thyroxine via diazo-coupling with diazotized p-nitroaniline. Int J Enhanc Rese Sci Tech Eng 2015;4:290-5.

7. Othman NS. Spectrophotometric determination of cephadroxil by coupling with diazotized $\mathrm{p}$ nitroaniline application to pharmaceutical preparations. Tikrit J Pure Sci 2006;11:187-9.

8. Kadir AN. Spectrophotometric determination of vitamin B6 by coupling with diazotized p-nitroaniline. Rafidain J Sci 2010;21:49-59.

9. Sinan R, Al-Abachi MQ. Batch and flow-injection spectrophotometric methods for determination of paracetamol in pharmaceutical preparations by coupling with diazotized 4-nitroaniline. Iraqi J Sci 2008;49:12-20.

10. Saunders KH, Allen RL. Aromatic Diazo Compounds. $3^{\text {rd }}$ ed. UK: Edward Arnold; 1985. p. 368-69.
11. Prasad GG, Nadh RV. Determination of mianserine using $\mathrm{Fe}^{3+}$-phenanthroline by visible spectrophotometry. Res J Pharm Tech 2019;12:22-7.

12. Prasad GG, Nadh RV. Oxidative Coupling: A tranquil approach for determination of selexipag by visible spectrophotometry. Oriental J Chem 2018;34:3112-7.

13. Regitz M. Diazo Compounds: Properties and Synthesis. New York: Elsevier; 2012. p. 96-108.

14. Sandler SR, Karo W. Diazo and diazonium compounds. In: Source Book of Advanced Organic Laboratory Preparations. Ch. 15. New York: Academic Press; 2012. p. 147-55.

15. Kosenkov D, Slipchenko LV. Solvent effects on the electronic transitions of p-nitroaniline: A QM/EFP study. J Phys Chem A 2010;115:392-401.

16. Board NI. Drugs and Pharmaceutical Technology Handbook. New York: Asia Pacific Business Press Inc.; 2004. p. 69-74.

17. Smith GA, King DA. Determination of the steamvolatile phenols present in cigarette-smoke condensate. Part I. Colorimetric determination of the total steamvolatile phenols. Analyst 1964;89:305-11.

18. Barlin GB. Introduction to pyrazines. In: Chemistry of Heterocyclic Compounds: The Pyrazines. Ch. 1. Vol. 41. John Wiley and Sons; 2008. p. 1-10.

19. Christian GD. Anal Chem. $5^{\text {th }}$ ed. New York: Wiley; 1994. p. 385-6.

20. Guideline IH. Validation of Analytical Procedures: Text and Methodology In: International Conference on Harmonization, Geneva, Switzerland; 2005. p. 11-2.

21. Sethi PD. HPLC Quantitative Analysis of Pharmaceutical Formulations. CBS Publications and Distributors. $1^{\text {st }} \mathrm{ed}$. India: CBS Publishers and Distributors; 2001. p. 69-70.

22. Prasad GG, Nadh RV. Determination of mianserine using tropaeoline-OOO by ion pair formation. Int J Appl Pharm 2019;11:714-6.

23. Kiran KK, Nadh RV, Nagoji KE. Extractive spectrophotometric determination of nicergoline through ion-pair complexation reaction. Orient J Chem 2013;29:263-9.

24. Sudhir MS, Nadh RV. Simple and validated ultraviolet spectrophotometric method for the estimation of febuxostat in bulk and pharmaceutical dosage forms. Orient J Chem 2013;29:1507-14.

25. Kiran KK, Nadh RV, Nagoji KE. Determination of bendamustine hydrochloride in pure and dosage forms by ion-associative complex formation reaction. Orient $\mathrm{J}$ Chem 2014;30:905-10.

26. Prasad GG, Nadh RV, Kiran KK. Piperacillin estimation by ion-associative complex formation. Asian J Pharm Clin Res 2019;12:293-300.

27. Prasad GG, Nadh RV, Kiran KK. Ion-associative complex formation for estimation of piperacillin. Int $\mathrm{J}$ Res Pharm Sci 2019;10:89-92.

Source of Support: Nil. Conflict of Interest: None declared. 